\title{
EDUKASI PENCEGAHAN INFEKSI SALURAN KEMIH (SIRKUMSISI) \\ PADA ORANG TUA DAN ANAK USIA SEKOLAH \\ JAMAAH MASJID DARUSSALAM BENGKURING KOTA SAMARINDA
}

\author{
Rita Pupa Sari ${ }^{1^{*}}$, Ruminem², Bachtiar ${ }^{3}$, Mayusef Sukmana ${ }^{4}$, Iskandar Muda $^{5}$, \\ M.Aminuddin ${ }^{6}$, Dwi Nopriyanto ${ }^{7}$ \\ ${ }^{1-7}$ Universitas Mulawarman \\ Email Korespondensi: r.puspasari1172@gmail.com
}

Disubmit: 27 Juli 2021 Diterima: 11 Agustus $2021 \quad$ Diterbitkan: 04 Februari 2022 DOI: https://doi.org/10.33024/jkpm.v5i2.4729

\begin{abstract}
ABSTRAK
Kegiatan pengabdian kepada masyarakat dengan pemberian edukasi berupa penyuluhan tentang Pencegahan Infeksi Saluran Kemih pada orang tua dan anakanak yang dilakukan sirkumsisi adalah bentuk perhatian petugas Kesehatan dalam melakukan pencegahan masalah Kesehatan yang mungkin timbul di kelompok masyarakat. Edukasi yang diberikan kepada orang tua dan anak yang dilakukan sirkumsisi diharapkan mampu mencegah infeksi saluran kemih dengan dilakukan sirkumsisi dan cara perawatan dirumah pasca tindakan sirkumsisi serta menambah pengetahuan tentang penyakit infeksi yang dapat terjadi pada anakanak. Tujuan dilakukannya kegiatan ini adalah untuk memberikan pengetahuan tentang pencegahan infeksi saluran kemih serta perawatan pasca sircumsisi yang dibutuhkan oleh orang tua dan anak yang dilakukan sirkumsisi. Kegiatan ini dilakukan pada tanggal 23 Juni 2021 di Ruang Minihospital Laboratorium Keperawatan Prodi D3 Keperawatan Fakultas Kedokteran Universitas Mulawarman, dengan sebanyak 30 orang tua dan 15 anak. Kegiatan edukasi yang dilakukan berupa penyampaian materi tentang pencegahan infeksi saluran kemih dan perawatan pasca sircumsisi dirumah. Kegiatan ini membawa dampak yang positif dilingkungan kelompok masyarakat yaitu dengan bertambahnya pengetahuan orang tua dan anak yang ditunjukkan dengan mereka mampu menjawab pertanyaan-pertanyaan yang diajukan oleh pemateri serta atas permintaan pengurus masjid agar dapat dilaksanakan juga edukasi untuk remaja masjid, melihat antusiasme seperti ini perlu kiranya diberikan edukasi dengan materi lainnya yang memang sangat diperlukan dalam meningkatkan Kesehatan keluarga dan masyarakat.
\end{abstract}

Kata Kunci: Edukasi, Infeksi saluran kemih, Sirkumsisi

\begin{abstract}
Community service activities by providing education in the form of counseling about the prevention of Urinary Tract Infections for parents and children who have circumcision are a form of concern for health workers in preventing health problems that may arise in community groups. The education given to parents and children who underwent circumcision is expected to be able to prevent urinary tract infections by doing circumcision and how to take care at home after circumcision and increase knowledge about infectious diseases that can
\end{abstract}


occur in children. The purpose of this activity is to provide knowledge about the prevention of urinary tract infections and post-circumcision care needed by parents and children undergoing circumcision. This activity was carried out on June 232021 in the Minihospital Room of the Nursing Laboratory of the D3 Nursing Study Program, Faculty of Medicine, Mulawarman University, with as many as 30 parents and 15 children. Educational activities were carried out in the form of delivering materials on the prevention of urinary tract infections and post-circumcision care at home. This activity has a positive impact on the community group, namely by increasing the knowledge of parents and children which is shown by their being able to answer the questions posed by the presenters and at the request of the mosque management so that education can also be carried out for mosque youth, seeing enthusiasm like this is necessary. given education with other materials that are needed in improving the health of families and communities.

Keywords: Education, Urinary tract infection, Circumcision

\section{PENDAHULUAN}

Pengetahuan tentang pencegahan penyakit dan perawatan anak sakit dirumah sangat diperlukan oleh orang tua, karena orang tua adalah orang terdekat yang membantu tugas perkembangan anak, sehingga orang tua bertanggung jawab pola asuh anak untuk menjaga Kesehatan anak. (Dewi, 2011).

Personal hygiene sebagai salah satu pencegahan terjadinya infeksi harus dipahami dan dibiasakan dilakukan dalam upaya pemeliharaan Kesehatan keluarga. Riset Kesehatan Dasar yang telah dilakukan oleh kemenkes diperoleh informasi bahwa Indonesia menempati urutan ketujuh kematian, yang disebabkan infeksi karena kurangnya personal Hygiene yaitu 5,7\% dengan prevalensi 43/1000 penduduk (Kemenkes RI, 2013).

Prevalensi ISK pada anak usia sekolah di Indonesia 1-3\%, 200 anak usia sekolah di Indonesia menderita ISK atau sekitar 33\% pada anak laki-laki (Pamungkas, 2012). Selain ISK, personal Hygiene genetalia yang kurang dapat menyebabkan balanitis. Balanitis biasa terjadi pada seseorang yang tidak melakukan sirkumsisi. Terjadi peradangan pada glans penis karena tidak menarik kulup untuk membersihkan kepala penis sehingga menyebabkan akumulasi smegma yang menjadi penyebab inflamasi dan selanjutnya menyebabkan phimosis. (Bostwick, 2019).

Menurut Dewi (2011) Salah satu aktifitas kebersihan diri diantaranya adalah kebersihan genetalia dan perineal atau personal hygiene genetalia. Kebersihan genetalia atau personal hygiene genetalia ini juga diartikan oleh Black (2009) yaitu merupakan perawatan yang meliputi kebersihan genetalia yang dilakukan diri sendiri. Personal Hygiene genetalia adalah Perawatan kebersihan genetalia yang dilakukan untuk mencegah infeksi yang disebabkan oleh bakteri, karena organ genetalia rentan terhadap infeksi.

Selain kurang memahami pencegahan infeksi ada pula Sebagian orang tua Yang kurang mengetahui cara perawatan luka sirkumsisi. Pengetahuan merupakan hasil "tahu" dan ini terjadi setelah orang melakukan pengindraan terhadap suatu subyek tertentu. Pengindraam terjadi melalui panca indera manusia.

Penelitian tentang Pengetahuan orang tua pada anak yang dilakukan khitan yang dilakukan pada 60 orang tua yang memiliki anak usia 6-12 tahun 
baik yang dikhitan maupun belum dikhitan menggambarkan hasil bahwa pengetahuan orang tua kurang sebanyak $51,67 \%$, pengetahuan cukup $30 \%$ dan pengetahuan yang baik 18,33\% (Azizah, 2015).

Sirkumsisi atau sunat atau disebut juga khitan adalah suatu Tindakan pembuangan dari Sebagian atau seluruh kulup (prepusium) penis dengan tujuan tertenti. Sirkumsisi merupakan prosedur pembedahan yang paling umum dilakukan pada laki-laki karena sirkumsisi rutin pada bayi untuk alas an agama dan budaya (saswita,2017).

Berdasarkan sejarah, banyak sekali kebudayaan yang telah melakukan sunat untuk alasan Kesehatan, sebagai tanda peralihan menuju kedewasaan, sebagai tanda identitas budaya (mirip dnegan tattoo) atau sebagai ritual korban kepada dewa. Ritual sirsumsisi ini telah lama dipraktekkan dan telah membudaya pada daerah timur tengah. Pada akhir abad 19 ritual ini telah menjadi suatu praktek dengan alas an medis (Angel, 2014).

Sirkumsisi pada laki-laki memberikan efek proteksi bagi penularan penyakit infeksi menular seksual tapi tidak berarti dapat menggantikan upaya pencegahan penularan IMS lainnya. (Fitria, 2014).

Sirkumsisi merupakan Tindakan bedah yang meninggalkan luka yang bisa cukup mengganggu bagi anak. Hal ini dikarenakan adanya rasa nyeri dan terbatasnya Gerakan yang membuat anak merasa tidak nyaman. Luka sirkumsisi seharusnya sembuh dalam beberapa hari, namun beberapa hal dapat menyebabkan penyembuhan luka menjadi lebih lama. Salah satu komplikasi sirkumsisi yang sering terjadi adalah infeksi. (Prasetyo,2018).

Perlu diberikan edukasi kepda orang tua dan anak-anak yang dilakukan sirkumsisi agar kejadian buruk atau efek samping yang tidak dinginkan paska dilakukan sirkumsisi dapat disingkirkan, menurut Saswita (2014) menyampaikan bahwa setelah dilakukan Tindakan sirkumsisi perlu diperhatikan perawatannya, beberapa perawatan yang harus dilakukan paska sirkumsisi yaitu:

1. Pemberian obat analgesic dan antibiotic

2. Menjaga daerah alat kelamin tetap bersih dan kering

3. Mengatur makanan

4. Tidak perlu Tindakan berlebihan

5. Kontrol dan melepas perban

\section{MASALAH}

Berdasarkan hasil-hasil penelitian tentang pengetahuan orang tua terhadap perawatan luka paska sirkumsisi sebagian memiliki pengetahuan yang kurang, hal ini disebabkan orang tua khususnya ibu hanya mendapat informasi dari budaya seperti tidak boleh minum air banyak-banyak dan masih panik saat terjadi pembengkakan pada luka anak. Kurangnya pengetahuan ini dikarenakan Pendidikan ibu yang kurang sehingga dalam menyerap informasi juga kurang, atau kurang kooperatif dalam menanyakan tentang pencegahan infeksi dan perawatan luka sirkumsisi kepada petugas Kesehatan Kurang pengetahuan orang tua dan ibu ini membuat perawatan luka paska sirkumsisi menjadi kurang maksimal sehingga kadang terjadi keterlambatan dalam penyembuhan.

Dilingkungan masjid Darussalam banyak keluarga yang memiliki anak lakilaki usia sekolah SD dan kebanyakan merupakan keluarga dengan perekonomian menengah kebawah. Sehingga sangat tepat dijadikan sasaran 
untuk kegiatan pengabdian masyarakat yag dilakukan oleh prodi D3 keperawatan fakultas kedokteran Universitas Mulawarman.

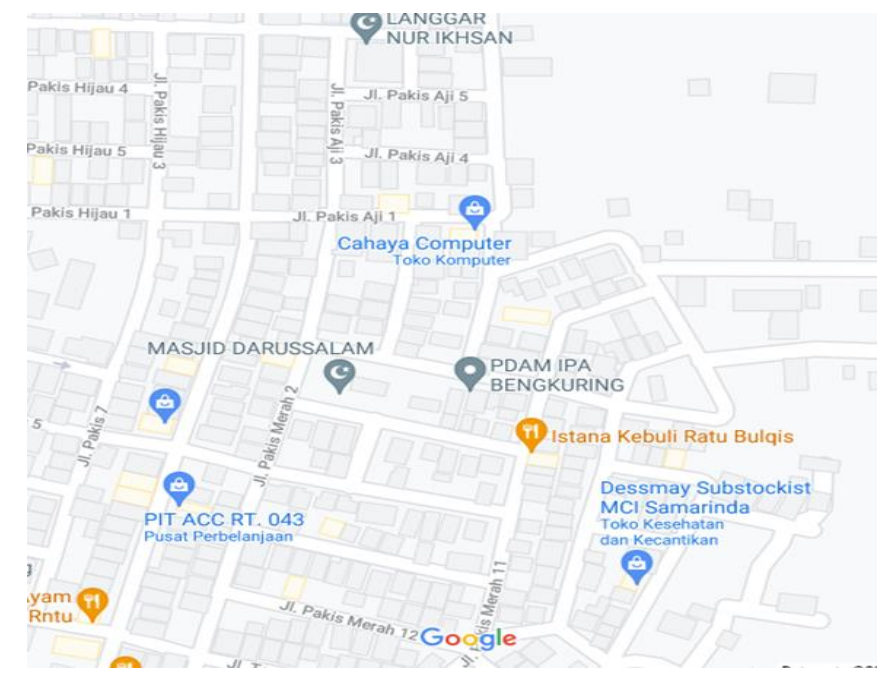

Gambar 1. Peta lokasi Tempat tinggal Subyek/sasaran

\section{METODE}

Kegiatan edukasi ini dilaksanakan sebelum anak-anak dilakukan sirkumsisi untuk memudahkan sasaran menerima informasi dan agar bisa lebih focus dalam mendengarkan informasi yang diberikan.

Subyek dalam kegiatan ini adalah Orang tua dan anak-anak yang akan dilakukan sirkumsisi yang merupakan jamaah masjid Darussalam Perumnas Bengkuring Sempaja Timur Kecamatan Samarinda Utara Kota Samarinda.

Kegiatan Pengabdian Kepada Masyarakat ini dilakukan melalui tahapan perencanaan yaitu dengan menjalin komunikasi dan menghasilkan kesepakatan untuk bersama pengurus masjid Darussalam Bengkuring Samarinda melaksanakan Edukasi berupa Penyuluhan kepada kelompok masyarakat, selanjutnya Menyusun rencana kegiatan pelaksanaan penyuluhan dengan mempersiapkan tempat untuk melaksanakan penyuluhan, menyiapkan materi penyuluhan serta mempersiapkan alat transfortasi untuk membawa para orang tua dan anak-anak yang dilakukan sirkumsisi ke lokasi penyuluhan dan pelaksanaan sirkumsisi berlangsung. Langkah-langkah dalam pelaksanaan edukasi diawali dengan mengajukan pertanyaan-pertanyaan interaktif seputar apa saja yang diketahui orang tua dan anak perilaku pencegahan infeksi yang dilakukan dirumah selama ini dan alasan orang tua dan anak melakukan sirkumsisi pada anak-anak diusia sekolah 6-12 tahun serta menggali pengetahuan orang tua tentang perawatan luka sirkumsisi yang dilakukan dirumah dan personal hygiene alat kelamin paska sirkumsisi pada anak-anak yang akan dilakukan sirkumsisi. Selanjutnya tim pengabdian masyarakat yang melakukan penyampaian materi, untuk memudahkan menggunakan media slide (ms.power point) selama 40 menit, setelah penyampaian materi diberikan pertanyaanpertanyaan interaktif kepada orang tua dan anak-anak yang akan dilakukan sirkumsisi. 


\section{HASIL DAN PEMBAHASAN}

Edukasi kepada kelompok masyarakat jamaah masjid Darussalam yaitu orang tua dan anak yang dilakukan sirkumsisi tentang Penyuluhan Pencegahan Infeksi Saluran Perkemihan Pada Anak dihadiri 30 orang tua dan15 anak-anak.

Hasil dari kegiatan ini adalah orang tua dan anak-anak yang mendengarkan penyuluhan terlihat antusias menyimak materi yang disampaikan oleh tim pengabdian masyarakat. Rata-rata peningkatan pengetahuan subyek atau sasaran tentang bagaimana melakukan perawatan paska sirkumsisi dan bagaimana mencegah terjadinya infeksi saluran perkemihan adalah $80 \%$ (dalam kategori sangat baik).

Tidak ada hambatan yang berart yang ditemukan selama pelaksanaan edukasi berlangsung. Tim pengabdian masyarakat terus melakukan pendekatan dan pemantauan terhadap pengetahuan orang tua melalui wawancara langsung dan melalui telepon seluler pada kondisi luka paska sirkumsisi pada anak-anak yang dilakukan sirkumsisi.
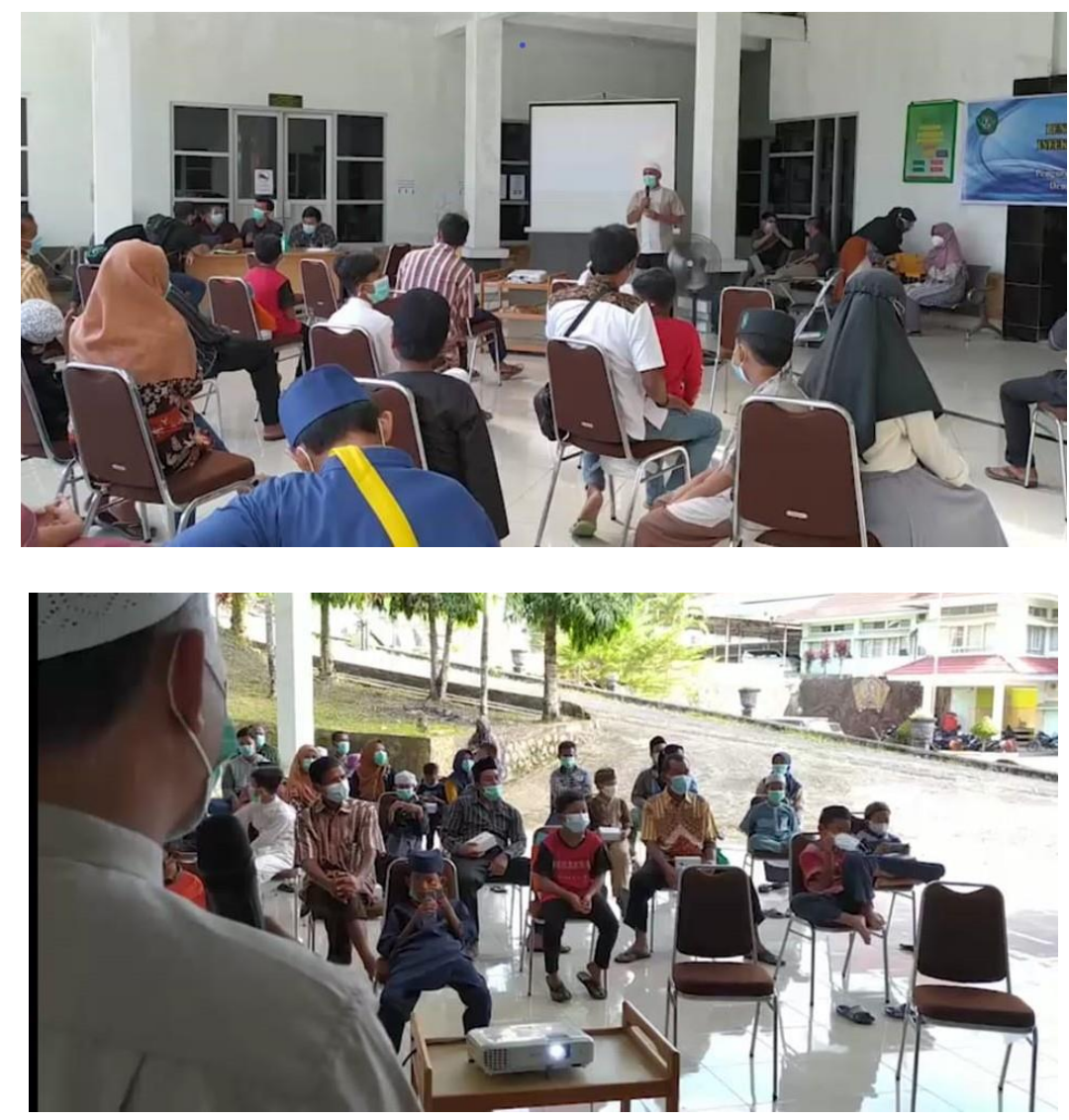

Gambar 2. Foto Kegiatan edukasi : Penyuluhan Pencegahan Infeksi Saluran Kemih

\section{KESIMPULAN}

Kesimpulan dari kegiatan pengabdian masyarakat yang bertemakan Pencegahan Infeksi Saluran Kemih yang dilakukan pada orang tua dan anakanak yang dilakukan sirkumsisi. Dari pembahasan uraian diatas dapat 
disimpulkan bahwa Sirkumsisi harus dilakukan pada anak laki-laki sebagai salah satu cara untuk mencegah terjadinya IMS dan perawatan luka paska sirkumsisi dan personal hygiene alat kelamin harus dilakukan dengan benar oleh orang tua dan anak agar terhindar dari infeksi saluran kemih yang dapat terjadi pada anak laki-laki.

\section{DAFTAR PUSTAKA}

Angel CA. (2014). Circumcision: Background, Pathophysiologi, Epidemiology. Emedicine. Medscape.com http://emedicine.medscape.com/article/1015820-overview

Azizah Fidrotin, Ahmad Maftukhin \& Nikmatuj Fajriyah. (2015). Gambaran Pengetahuan orang tua (Ibu) tentang perawatan luka sirkumsisi pada anak usia sekolah (6-12 tahun).e-journal Stikes Rejekwesi Bjonegoro 6(1), 1-5.http://ejournal.rajekwesi.ac.id/index.php/jurnalpenelitian-kesehatan/article/view/82

Black, JM., \& Hawks, JH. (2009). Medical-Surgical Nursing : Clinical Management for Positive Outcomes. Vol. 1. Ed. 8. St. Louis Missouri : Saunders Elseiver.

Prasetyo Bondan. (2018). Asupan Seng dan penyembuhan luka sirkumsisi. JNH Journal of Nutrution and Health 6(2), 93-98. https://doi.org/10.14710/jnh.6.2.2018.93-98

Bostwick, DG \& Liang C. (2019). Urologic Surgical Pathology. Fourth Edition. Philadelphia: Elsevier Saunders. ISBN : 978-0-323-54941-7

Departemen Kesehatan RI. (2013). Riset Kesehatan Dasar. Jakarta: Badan Penelitian dan Pengembangan Kesehatan Kementrian Kesehatan RI. Diakses dari https://www.litbang.kemkes.go.id/laporan-risetkesehatan-dasar-riskesdas/

Dewi, RS. (2011). Determinan Status Higienitas Genetalia Mahasiswi di Universitas Wiayah Depok. Masters thesis. Universitas Indonesia. Diakses dari http://lib.ui.ac.id/file?file=digital/20282129T\%20Ratna\%20Sari\%20Dewi.pdf

Fitria. (2014). Peran Sirkumsisi dalam Infeksi Menular Seksual. Jurnal Kedokteran Syiah Kuala 14(1), 43-49.

http: / / jurnal.unsyiah.ac.id/JKS/article/view/3273

Saswita Yeni. (2017). Hubungan tingkat pengetahuan orang tua dengan sikap terhadap perawatan luka paska sirkumsisi pada anak laki-laki di desa Gunung Hasahatan dan desa Ujunggurap. Universitas Sumatera Utara http://repositori.usu.ac.id/handle/123456789/19803

Pamungkas, ED. (2012). Faktor-faktor yang Berhubungan dengan gejala infeksi Saluran Kemih pada Anak Usia Sekolah di SDN Pondok Cina 1 Depok. Fakultas IImu Keperawatan Universitas Indonesia. http: / /lib.ui.ac.id/file?file=digital/20301763-S42033Eny\%20Dewi\%20Pamungkas.pdf 